\title{
ANSYS Based Simulation of Single and Double Coil Axial Active Magnetic Bearing using Finite Element Method
}

\author{
Jonathan Laldingliana, Pabitra Kumar Biswas
}

\begin{abstract}
For the successful design of an AMB system, proper material selection and actuator design is a must. The strength of the magnetic force depends upon the current density of the winding, actuator dimension and the gap between the actuator and the rotor. This paper presents the design of a $\mathrm{U}-\mathrm{O}$ type single-actuator and a double-actuator Active Magnetic Bearing (AMB) utilizing ANSYS Maxwell 17.1 software. In double actuator $A M B$ the actuators are placed at 180 degrees apart. In this study, Finite Element Method (FEM) based simulation has been performed for two different structures and their magnetic properties for instance- flux pattern, force, flux density and inductance are obtained for various air-gaps. Analysis has also been done with the change in current density by varying in the coil turns. The comparative results of single and double coil AMB are illustrated in 2-D and 3-D plots.
\end{abstract}

Keywords: Electromagnetic field, flux pattern, active magnetic bearing (AMB), finite element method (FEM), ANSYS Maxwell.

\section{INTRODUCTION}

As opposed to traditional bearing, magnetic bearing drifted a rotating part with no substantial contact, which gives a relative motion between the stator and the rotor with no friction [1]. The speed conveyed by the magnetic bearing is the most essential of a wide scope of bearing, it has low vibration level, high precision, soundless and long-running life e turning part [2,3]. Magnetic bearing is differentiated into two types- Passive Magnetic Bearing which used permanent magnet and an Active Magnetic Bearing which utilized electromagnet. As indicated by Earnshaw's hypothesis, it is hard to control a magnetic bearing utilizing permanent magnets since it has a fixed attractive property [4]. In contrast, in an active magnetic bearing with the change in the actuator current and the coil turns, the magnetic properties can be changed. Therefore, in many industrial applications, Active magnetic bearing is chosen over a passive magnetic bearing. The block diagram of an Active Magnetic Bearing system is shown in figure 1. AMB system consists of the following blocks-

\footnotetext{
Revised Manuscript Received on February 05, 2020. * Correspondence Author

Jonathan Laldingliana, EEE Department, National Institute of Technology Mizoram, Aizawl, Mizoram, India

Pabitra Kumar Biswas, EEE Department, National Institute of Technology Mizoram, Aizawl, Mizoram, India.
}

(C) The Authors. Published by Blue Eyes Intelligence Engineering and Sciences Publication (BEIESP). This is an open access article under the CC BY-NC-ND license (http://creativecommons.org/licenses/by-nc-nd/4.0/)
1. Stator: It is the stationary of an AMB system; insulated copper wire is wounded in the core of a stator. The electromagnetic force created by the stator relies on the loop current and the number of coil turns.

2. Rotor: It is a moving part of the system, rotor floats and rotates in the air at very high speed when it is in the equilibrium position.

3. Sensor: The gap between the rotor and the stator is determined by the sensor and the information provided by the sensor is transfer to the controller.

4. Controller: It controls the necessary measure of current coursing through the stator coil.

The electrical equation of a single coil AMB is illustrated in equation 1.

$e=R . I+L \frac{\delta I}{\delta t}-L_{0} z_{0} \frac{\delta z}{\delta t}$

Where, $e=$ voltage across the coil; $R=$ coil resistance; $L$ $=$ coil inductance; $z=$ rotor position; $z_{0}$ and $L_{0}$ are nominal operating constants.

The fundamental target of an AMB is to create an essential magnetic force to float the rotor situated in the bearing. The force produced by the electromagnet is the gradient of the magnetic field energy and relies upon the air gap. [5].

$F=-\frac{d w}{d g}$

Where, $w==\frac{1}{2} \oint_{m} \frac{B^{2}}{\mu_{0}} d A$.

Here, ' $F$ ' is the magnetic force, ' $A$ ' is the air-gap volume and $' w$ ' is the magnetic field energy.

The force equation for single-axis and double-axis AMB are given in equation 3 and 4 [6].

$F_{\text {single }}=\frac{N_{\text {tu }}^{2} \mu_{0} A_{\text {air }}}{4}\left[\frac{I(t)}{g(t)}\right]^{2}$

$F_{\text {double }}=\frac{N_{\text {tu }}^{2} \mu_{0} A_{\text {air }}}{4}\left[\frac{\left(I_{b}+I_{c o}\right)^{2}}{\left(g_{0}-g\right)^{2}}\right]-\left[\frac{\left(I_{b}-I_{c o}\right)^{2}}{\left(g_{0}+g\right)^{2}}\right] \cos \theta$

Whereas, $N_{t u}$ is the number of actuator coil turns, $\mu_{0}$ is the air permeability, $A_{\text {air }}$ is the air-gap cross-sectional area, $I(t)$ is the actuator coil current, $i_{0}$ is the nominal current and $i_{c}$ is the control current, $g$ is the air-gap between rotor and the actuator whereas $g_{0}$ is the nominal air-gap. $\theta$ is the angle between the center of the cross section and the force direction. 


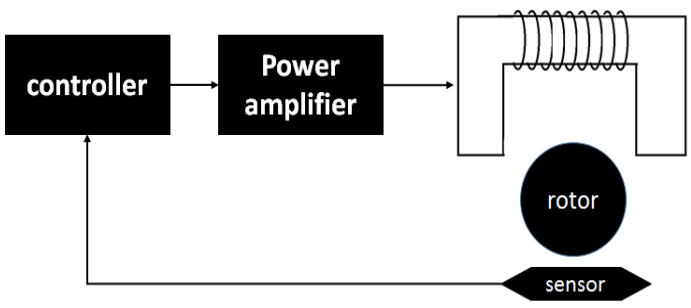

Fig. 1: Block diagram of Single coil AMB system

In this paper, simulation has been carried out for two different structures- single-axis AMB and double-axis AMB system. In double-axis AMB, the two actuators are placed at 180 degrees apart. FINITE Element Method (FEM) based modelling and simulation software has been utilized to determine magnetic properties. The results obtained from the two models are compared in 2-D graphs as well as in 3-D graphs.

\section{ANSYS AND FINITE ELEMENT METHOD}

The finite element method (FEM) is the most generally utilized technique for taking care of issues of designing and scientific models. To solve a problem, the FEM subdivides a huge framework into littler, less complex parts that are called finite elements. Different technical issues such as- nonlinear and linear issues, transient, steady, liquefied flow, electromagnetism, heat transfer can be analyzed using FEM [6]. Basic steps involving in FEM are as follow: -

1. Pre-processing: A domain is separated into a limited number of parts for imposing mathematical equations on it named as Discretization also known as Meshing.

2. Solver: It includes applying boundary conditions and initial value generation. Various codes are set up to solve this mathematical equation.

3. Post-processing: The results generated are in numeric format. For perception reason, it is obligatory to represent the results in Graphics. This stage converts the numeric format into graphical format.

ANSYS Maxwell version 7.1 is utilizing for recreating the active magnetic bearing model. ANSYS gives an ideal workplace for an electromagnetic plant and it is based on Maxwell's equation. A wide scope of finite element analysis can be performed utilizing ANSYS. It is used for analyzing non-linear and linear system, static and complex system as well as dynamic analysis [7,8]. The flow chart for modelling and calculating different parameters using ANSYS Maxwell for single-axis AMB and two axis AMB utilizing ANSYS Maxwell 2-D model is shown in figure-2.

An issue in the static magnetic field is solvable utilising Maxwell equations [9], the differential form of Maxwell equations is delineated beneath: -

$$
\begin{aligned}
& \nabla X E=-\frac{\partial B}{\partial t} \\
& \nabla X H=J+\frac{\partial D}{\partial t}
\end{aligned}
$$

In Maxwell's equation for static magnetic field $\frac{\partial D}{\partial t}=0$. Subsequently, equation (5) can be composed as-

$$
\begin{aligned}
& \nabla X H=J \text { and } \nabla \cdot B=0 \\
& \text { Also, } \\
& B=\mu \mathrm{H}=H \mu_{0} \mu_{r}
\end{aligned}
$$

Form equation 4 and 5, equation 6 can be formed.

$\nabla^{2} A=\mu J$

Equation-7 is a Poisson's equation for a magnetic field [10]. Where $\mathrm{H}$ is magnetic field intensity, $\mathrm{J}$ is current density, $\mathrm{B}$ is magnetic flux density and $\mu$ is permeability. The parameters used in single-coil and double coils are the same. Figure 3 shows the basic diagram of single-coil U-type AMB.

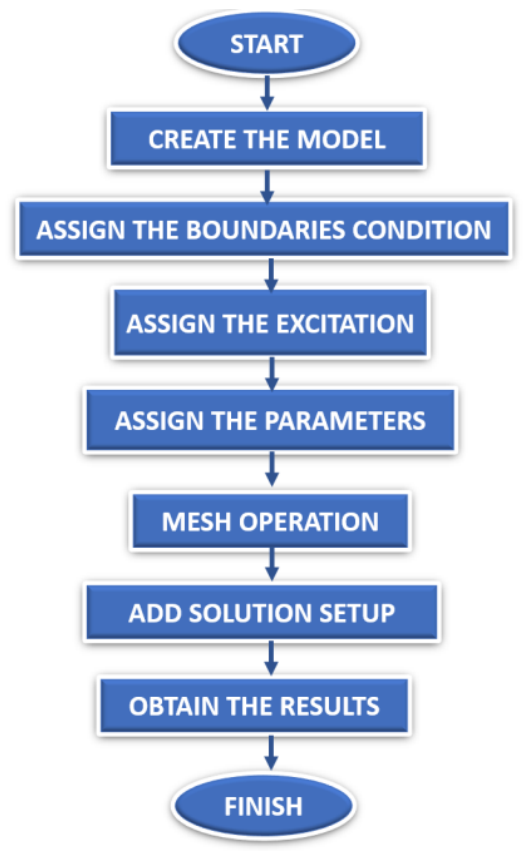

Fig. 2: Flow chart for calculation of different parameters using ANSYS Maxwell

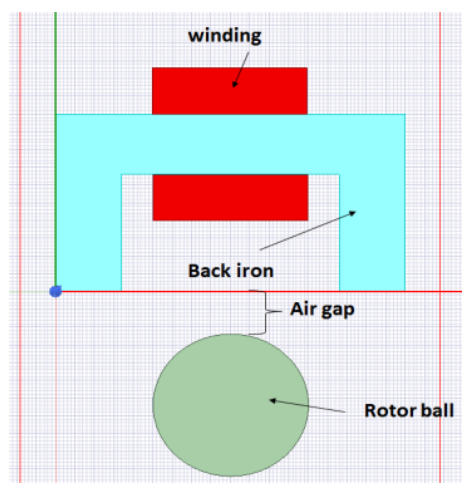

Fig. 3: Single coil U-type AMB

\section{SIMULATION RESULTS AND DISCUSSION:}

Finite Element Method based modelling and simulation software are utilized to analyze the Active Magnetic Bearing. Magnetic properties such as magnetic field, flux, flux density and magnetic force are analyzed for single axis and double axis active magnetic bearing.

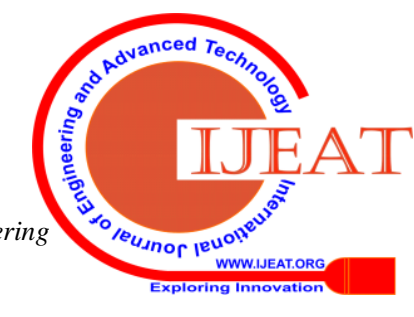


The inductance values are also obtained in this paper for both the prototype. In this section, ten diverse air-gap (2mm to 20mm) has been inspected utilizing ANSYS Maxwell 2-D modelling software. The materials utilized in the model and their properties are represented in table 1 and table 2 . Magnetic properties are plotted in vector form for $10 \mathrm{~mm}$ air gap, which is exhibited in figure 4 to figure 7 . Flux pattern for single and double axis AMB are shown in figure 4 and figure 5 illustrated the flux pattern and flux density visual plot. The vector plots of magnetic field are shown in figure 6 and force plots are shown in figure 7.

The characteristic of flux pattern, flux density and field for different air gaps between stator and rotor are plots in figure 8 to figure 10 in 2-D form. From figure 8 , maximum flux pattern is observed when the air-gap between the rotor and the actuators are in the least position which is $1.81 \mathrm{E}-03$ for single-axis AMB and 2.11E-03 for double-axis AMB. The amount of flux continues diminishing when the hole expanded due to the increased in leakage flux. It is likewise discovered that flux patter of double-axis AMB is more noteworthy than single-axis AMB due to the presence of a double actuator in the double-axis AMB model.

The value of flux density and magnetic field also diminished when the gap between the actuator and rotor expanded as given in figure 9 and 10 . Figure 11 illustrated the force plot for both the model. Since force is inversely proportional to the distance between the rotor and the stator. Therefore, it has been seen that the attractive force between the rotor and the actuator diminished with the expanded in the air-gap in both the model. At $2 \mathrm{~mm}$ airgap the force experienced by the rotor in single-axis AMB is $13.2 \mathrm{~N}$ while in double-axis AMB is only $0.2 \mathrm{~N}$. Double-axis AMB has experienced lesser force because of the force strength acquired by the two actuators placing at 180 degrees cancelling each other. While in single-axis AMB the forced obtained by the actuator has no counterforce in an ideal case. Consequently, single-axis AMB experienced higher force when contrasted with double-axis AMB.

In the following simulation study, the impact of current density is analyzed. The number of coil turns has differed for both the model and the $10 \mathrm{~mm}$ air gap is chosen. It has been affirmed that the electromagnetic force improved with the amplified in coil turns for 380 to 440 in both the case as illustrated in figure 12. The inductance plot has appeared in figure 13 . The inductance esteem slowly diminished with the expend in the gap between the rotor and the actuator. It is additionally seen that double-axis AMB has higher inductance value as compare to single-axis AMB this is due to the presence of mutual inductance.

Table 1: Parameters of the prototype.

\begin{tabular}{|l|l|l|l|}
\hline $\begin{array}{c}\text { SI } \\
\text { no }\end{array}$ & \multicolumn{1}{|c|}{ Items } & Description & \multicolumn{1}{|c|}{ Unit } \\
\hline 1 & \multirow{2}{*}{$\begin{array}{c}\text { Actuator } \\
\text { core }\end{array}$} & Material & Iron \\
\cline { 3 - 4 } & & Area & $2652 \mathrm{~mm}^{\wedge} 2$ \\
\cline { 3 - 4 } & & No. of edges & 8 \\
\cline { 3 - 4 } & & No of co-edges & 8 \\
\cline { 3 - 4 } & & No. of Vertices & 8 \\
\hline 2 & Actuator coil & Material & Copper \\
\hline
\end{tabular}

Table 2: Material properties:

\begin{tabular}{|l|l|l|l|l|}
\hline Material & $\begin{array}{l}\text { Bulk } \\
\text { Conductivi } \\
\text { ty }\end{array}$ & $\begin{array}{l}\text { Young's } \\
\text { Modul } \\
\text { us }\end{array}$ & $\begin{array}{l}\text { Poisson's } \\
\text { Ratio }\end{array}$ & $\begin{array}{l}\text { Relative } \\
\text { Permeability }\end{array}$ \\
\hline Iron & $\begin{array}{l}103 \mathrm{e} 5 \\
\text { siemens/m }\end{array}$ & $195 \mathrm{e} 9$ & 0.28 & 4000 \\
\hline Copper & $\begin{array}{l}58 \mathrm{e} 6 \\
\text { siemens/m }\end{array}$ & $12 \mathrm{e} 10$ & 0.38 & 0.99 \\
\hline Vacuum & 0 & - & - & 1 \\
\hline
\end{tabular}

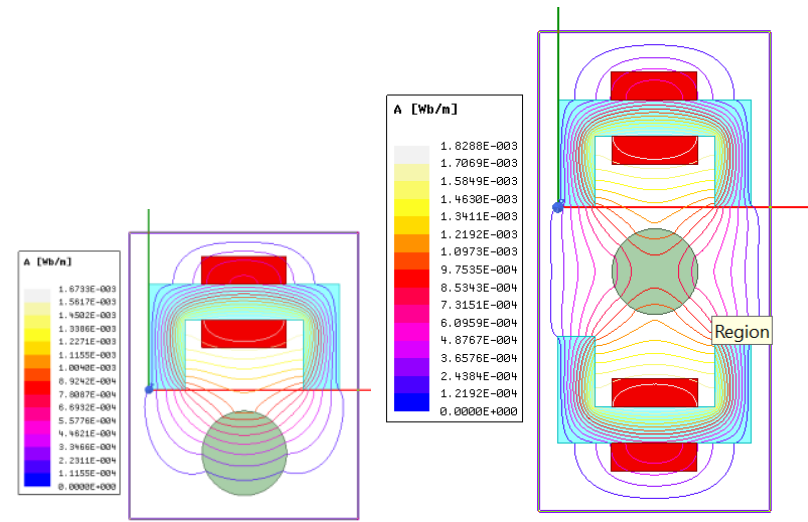

Fig. 4: Flux pattern of single and double axis AMB with airgap of $10 \mathrm{~mm}$

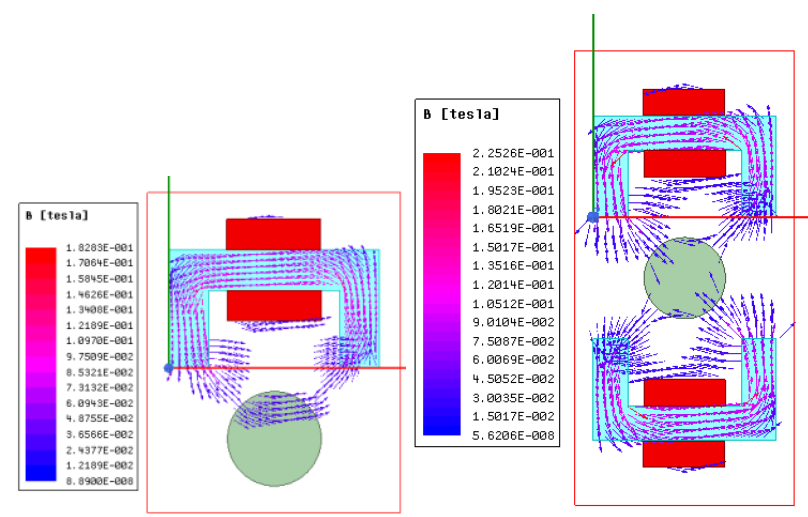

Fig. 5: Flux density for single and double axis AMB with airgap of $10 \mathrm{~mm}$

Published By:

Blue Eyes Intelligence Engineering

\& Sciences Publication 

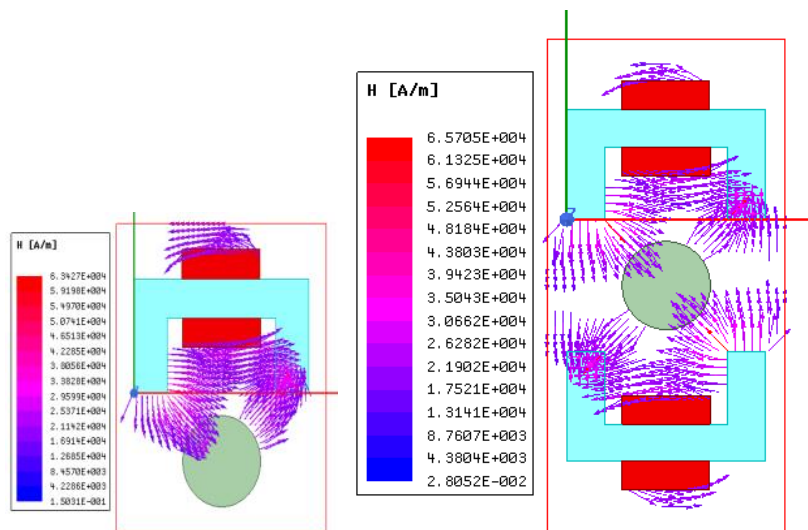

Fig. 6: Magnetic field for single and double axis AMB with airgap of $10 \mathrm{~mm}$

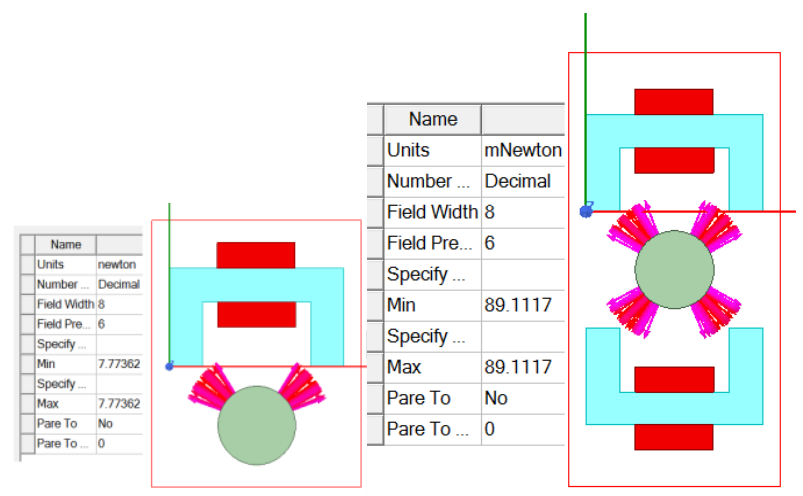

Fig. 7: Magnetic force for single and double axis AMB with airgap of $10 \mathrm{~mm}$

Flux vs airgap

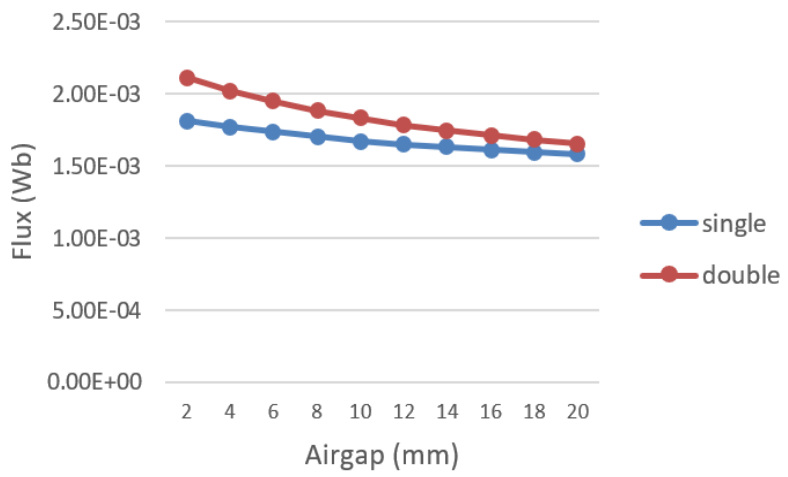

Fig. 8: Flux vs air gap for single axis and double axis AMB system

Flux density vs airgap

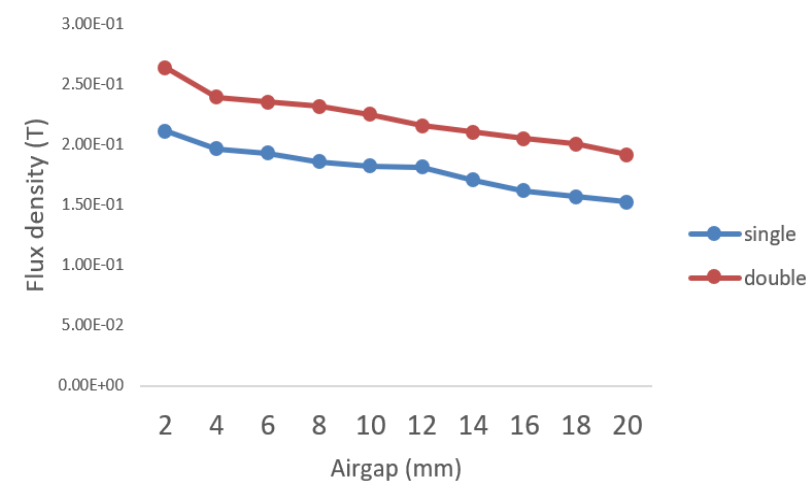

Fig.9: Flux density vs air gap for single axis and double

Retrieval Number: C5982029320 /2020@BEIESP axis AMB system

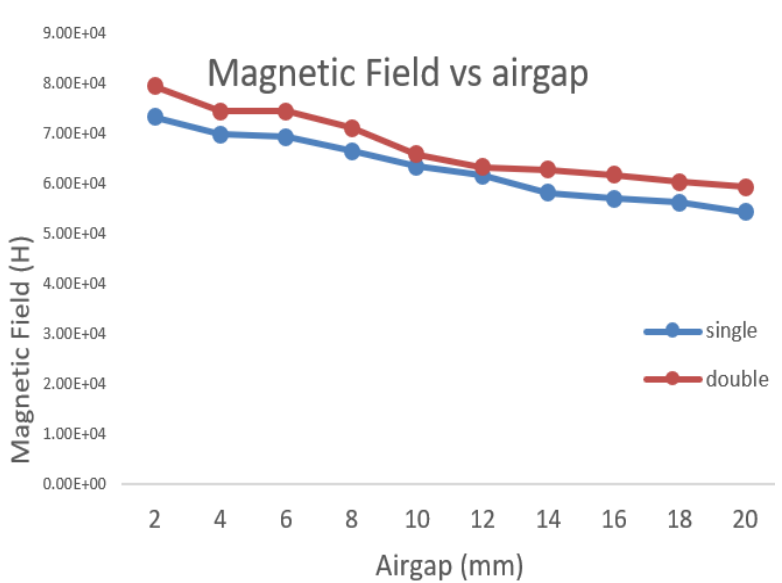

Fig. 10: Magnetic field vs air gap for single axis and double axis AMB system

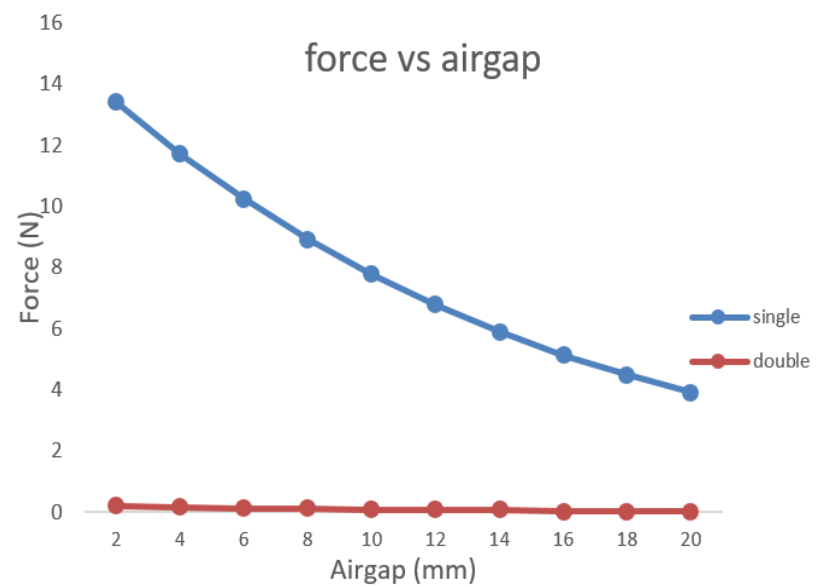

Fig.11: Force vs air gap for single axis and double axis AMB system

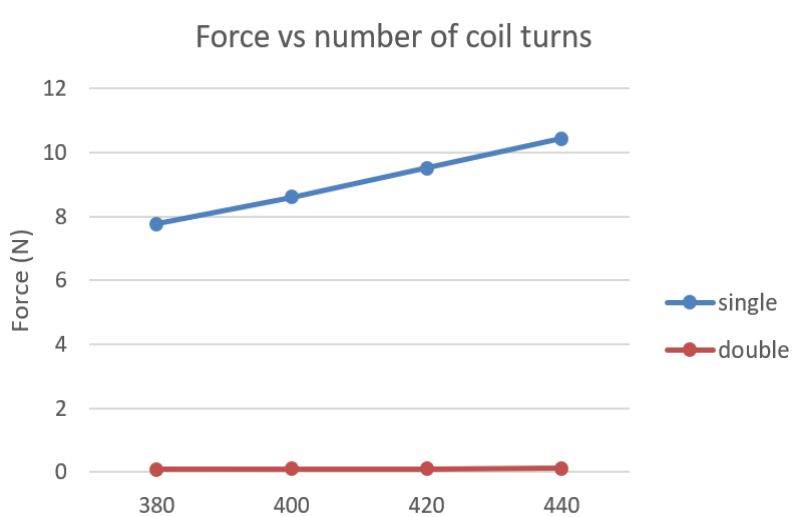

Coil turns in number

Fig. 12: Force vs number of coils turns for air gap10mm and current $3 \mathrm{~A}$
Published By:

Blue Eyes Intelligence Engineering

\& Sciences Publication 
Inductance Vs air gap

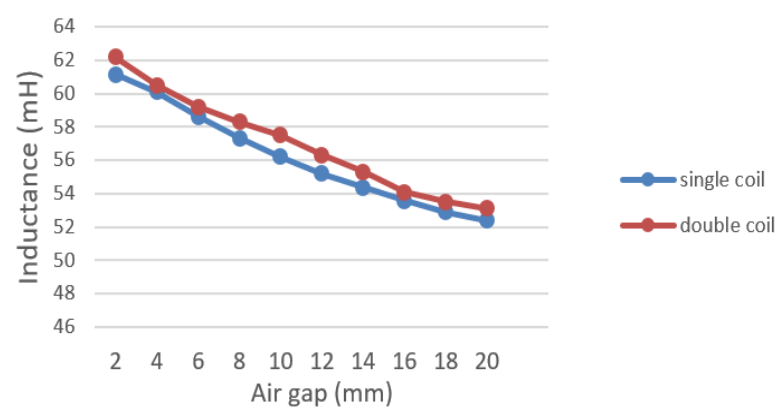

Figure 13: Inductance vs air gap for single and double axis AMB with current $3 \mathrm{~A}$

\section{CONCLUSION}

In this paper, the single axis and double axis AMB is simulated using ANSYS Maxwell 17.1 and results are presented. The work is focused on 2-D Finite Element analysis for two types of magnetic bearings inspect the performance in the real-time atmosphere. Simulation results for different air gap for single and double axis are presented and compared. The characteristic curves are drawn in 2-D as well as in the 3-D form. Is this study, it is observed that the value of flux and flux density is more in double-axis active magnetic bearing as well as a magnetic field. Electromagnetic force observed in the double-axis AMB is lesser as compared to single-axis AMB system. Inductance values are observed for different air-gaps, and it is found that inductance value decreased with increased in the air-gap. Comparing both the models, double-axis AMB more prominent inductance value due to the presence of mutual inductance.

\section{ACKNOWLEDGMENT}

The authors of this paper wish to show appreciation to Science and Engineering Research Board (SERB), DST, Government of India for economically backup the project.

\section{REFERENCES}

1. A. Pilat, "Selected magnetostatic analysis of 3-coil Active Magnetic Bearing", expert for the proceeding of the COMSOL User conference, prague, 2006.

2. J. C. Ji, and C. H. Hansen. "Non-linear oscillations of a rotor in active magnetic bearings." Journal of Sound and vibration 240, no. 4 (2001): 599-612.

3. S.E. Mushi., Z. Lin, and P.E. Allaire. "Design, construction, and modeling of a flexible rotor active magnetic bearing test rig." IEEE/ASME transactions on mechatronics 17.6 (2011): 1170-1182.

4. Tonks, Lewi. "Note on Earnshaw's theorem." Electrical Engineering 59, no. 3 (1940): 118-119.

5. J.P.A. Bastos and N. Sadowski, "Electromagnetic modeling by finite element methods". CRC press, 2003

6. Reddy, J. Narasimha. "An introduction to the finite element method." New York 27 (1993).

7. Low -frequency Electromagnetic analysis Guide, ANSYS, Inc., Release 12.1, 2009

8. ANSYS Inc., Licensing Guide, Release 12.1 (002829), November 2009.

9. Hammond P., Sykulski J.K., -Engineering Electromagnetism Physical Processes and Computationll, Oxford University Press, New York 1994.

10. N. G. Ivanov, A.B. Korsakov, E.M. Smirnov, K.V. Khodosevitch, V.V. Kalaev, Y.N. Makarov, E. Dornberger, J. Virbulis, and W. Von Ammon. "Analysis of magnetic field effect on 3D melt flow in CZ Si growth." Journal of Crystal Growth 250, no. 1-2 (2003): 183-188.

\section{AUTHORS PROFILE}

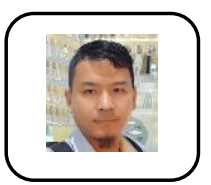

Jonathan Laldingliana, was born in Mizoram, India in the year 1989. He completed B.Tech. degree from North Eastern Regional Institute of Science and Technology (NERIST) in 2012 and crack a Graduate Aptitude Test in Engineering (GATE) in the year 2012. He pursues M.Tech from Visvesvaraya National nstitute of Technology (VNIT Nagpur) and got a degree in the year 2014. He is a former guest faculty in Mizoram University (2014 to 2016) and he is presently a fulltime $\mathrm{PhD}$ scholar at National Institute of Technology, Mizoram, India.

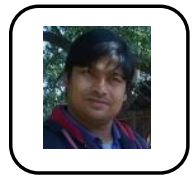

Pabitra Kumar Biswas, was born in West Bengal, India in 1980. He completed his B.Tech from Asansol Engg. College, WBUT, India. He received his Master of Engineering Degree from Bengal Engineering and Science University, West Bengal, India and PhD. Degree in Electrical Engineering from National Institute of Technology, Durgapur, India. He is presently working as Head of Department and Assistant Professor in Electrical Engineering in National Institute of Technology, Mizoram, India. He has published a numbers of research papers in National/International Conference Records/Journals. His research interests include Electromagnetic Levitation System, Active Magnetic Bearing, Power electronics and Machine Drives. 